\title{
(Re)centrando las Perspectivas Indígenas en la Educación Musical en América Latina
}

\author{
Héctor Miguel Vázquez Córdoba \\ University of Victoria (Canadá)/ Universidad Veracruzana (México)
}

Los conocimientos de los grupos indígenas han sido marginados y excluidos por medio de un sistema basado en una visión de mundo que perpetúa el colonialismo. Los estadosnación, con el apoyo de cuerpos académicos, reconocen y avalan formas del saber asumidas como "superiores", que marginan los conocimientos de las culturas indígenas. Es apremiante considerar una filosofía educativa que ponga al centro los saberes y cosmovisiones de las culturas locales. En este escrito, discuto la implementación de la propuesta filosófica de Styres (2017) centrada en la Tierra (Land-centred), en la educación musical. Esta postura parte de la premisa de que los conocimientos indígenas tienen la misma valía que los promovidos desde los centros hegemónicos occidentales. Esta perspectiva busca descentrar el papel del eurocentrismo que avala o niega formas del saber, al mismo que (re)centra los conocimientos indígenas y sus cosmovisiones.

Palabras clave: Fìlosofía centrada en la Tierra, educación musical, saberes indígenas.

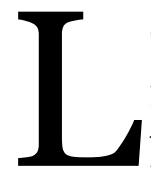

os pueblos indígenas en el continente Americano han sido oprimidos de manera sistémica durante siglos. De norte a sur, se dieron procesos de colonización, que tuvieron desenlaces como la exterminación de grupos indígenas, expulsión y apropiación de sus territorios ancestrales. La asimilación de la cultura dominante influyó de gran manera en la irreparable pérdida de gran parte la cultura y saberes de los pueblos originarios. La identidad de las culturas que alguna vez florecieron en el "Nuevo" continente (p.e., mayas, incas y aztecas) fue reconstruida desde la óptica del colonizador ${ }^{1}$, quien dio a éstas una identidad racial desde la visión eurocéntrica, concebida como "primitiva”, y que simplemente catalogó bajo un mismo nombre: indio(a) (Quijano 2000). El grupo social dominante que representa la cosmovisión del colonizador, le permite definirse a sí mismo y a

(C) Héctor Miguel Vázquez Córdoba. 2019. El contenido de este artículo es responsabilidad exclusiva del autor. La revista ACT y el MayDay Group no son responsables de cualquier acción legal que pueda surgir con respecto al contenido del artículo, incluyendo, pero no limitándose a, infracción de derechos de autor. 
los demás, y a su vez, afirma o niega la identidad de un grupo determinado dentro del contexto social (Giménez 2000). Diferentes personas y comunidades ejercen un musicar propio (Small 1998; MacDonald, Hargreaves y Miell 2002), por lo tanto, el aprecio o devalúo de sus músicas y maneras de vivenciarlas ofrece muestra clara del lugar que cada expresión musical guarda dentro del entramado social. En este contexto, la música de raíces indígenas es entendida como de menor valía si se compara con la de tradición europea, ya que la segunda representa la cosmovisión del colonizador (Shifres y Gonnet 2015). La huella del colonizador sigue vigente en la colonialidad, la cual privilegia una visión eurocéntrica impuesta en el imaginario de aquellos seres humanos que se conciben como dominados (Quijano 1992, 2000; Pujadas 2000; Rodríguez 2006; Rosabal-Coto 2013, 2014, 2016; Tutino 2000). Aunque es importante reconocer el origen de las desigualdades que históricamente han sido concebidas y aceptadas como válidas, es aún más importante vislumbrar espacios desde los cuales se puedan encauzar acciones concretas que promuevan una revaloración de las culturas indígenas y sus saberes. La educación musical presenta una oportunidad para incluir las perspectivas de las culturas indígenas. No es suficiente una mera trivialización que incluya repertorios o instrumentos, sino una colaboración activa con las personas portadoras de los saberes ancestrales.

Este artículo presenta una posición que toma como base la filosofía centrada en la Tierra ${ }^{2}$ (Land-centred) (Styres 2017), la cual pone en el centro de la conversación la perspectiva de los grupos indígenas y sus necesidades, bajo el entendido que los conocimientos que estas culturas albergan deben ser valorados a la par del conocimiento que representa el eurocentrismo, no como superior ni inferior. También, se hace una reflexión acerca del impacto que esta filosofía puede tener en la educación musical latinoamericana.

\section{Particularidades de la Colonización en el "Nuevo" Mundo}

En América Latina, el término indígena ha sido usado para subrayar y denotar la condición del ser colonizado, al cual se relega sistémicamente a vivir en una periferia política, económica y epistemológica (Garzón 2013). Entendiendo el sesgo que éste término trae al contexto particular de América Latina, considero importante que la palabra indígena en este artículo sea definida bajo la óptica propuesta por Wilson (2008), quien retoma el significado de esta palabra del Latín como

Vázquez Córdoba, Héctor Miguel. 2019. (Re)centrando las perspectivas indígenas en la educación musical en América Latina. Action, Criticism, and Theory for Music Education 18 (3): 172-99. http://doi.org/10.22176/act18.3.172 
"nacido de la tierra" o "que brota de la tierra", con la finalidad de presentar otra visión del término que refleje una relación estrecha entre las personas y su entorno (lugar físico), y a su vez contrarrestar la retórica que implica esta palabra en forma despectiva.

Los pueblos indígenas y sus culturas han sido amenazados desde el arribo de los colonizadores europeos al continente americano. Desde la visión eurocéntrica, el continente americano era un mundo nuevo, que existe solo hasta que es confirmado su descubrimiento por el colonizador europeo, quien tuvo como responsabilidad el poblar y proveer cultura a un territorio que carecía de éstas (Quijano 2000; Styres 2017). Además de estar basados en un control militar y político, los procesos de colonización en Latinoamérica implicaron una colonización simbólica, de índole religioso, apuntalada por la Iglesia Católica. El salvar las almas de los indígenas se vuelve la excusa perfecta para justificar la ocupación de tierras y explotación de aquellos que son considerados salvajes (Rosabal-Coto 2016; Sturman 2016). Los grupos originarios sufrieron un genocidio cultural (Quijano 1992) al ser reprimidos en sus cosmovisiones, y brutalmente sometidos y exterminados, debido a enfermedades que los colonizadores propagaron. No es posible hablar de un solo proceso de colonización que explique lo ocurrido históricamente a lo largo del continente, y las repercusiones que siguen vigentes producto de la imposición de formas de entender el mundo, opuestas a las visiones de las culturas indígenas. Este texto no alcanzará a explicar los procesos de conquista que se dieron en todos los puntos de Latinoamérica, así como las consecuencias que estos procesos tuvieron en las diversas culturas y los seres humanos portadores de estas. Expuesta esta limitación, se pretende abordar el tema desde una perspectiva general, para establecer un punto de inicio para la discusión del problema.

En el caso de los territorios ocupados por el Imperio Español, los colonizadores sometieron a las poblaciones indígenas como fuerza de trabajo. Para esto, hicieron uso de estructuras de relaciones serviles que operaban previo a la colonia. Con dicha práctica, los españoles se aseguraban el pago de un tributo, negociado a través de las élites indígenas; a cambio, estas últimas mantenían cierto control sobre los territorios y el resto de la población indígena (Beaucage 2000; Quijano 2000; Tutino 2000). Esta práctica favoreció la continuación de cacicazgos ${ }^{3}$ que ya existían previo a la llegada de los europeos, y también la formación de nuevos cacicazgos dentro de las poblaciones indígenas. Esto permitió que los colonizadores pudieran controlar vastas cantidades de tierras con relativamente poca presencia de 
representantes de la Corona Española. Beaucage (2000) señala que los colonizadores portugueses, en el territorio que ahora ocupa Brasil, después de someter por un tiempo a las poblaciones indígenas como fuerza de trabajo, optaron por exterminar y desplazar a las poblaciones nativas, y en su lugar remplazarles con esclavos traídos desde África. De acuerdo con Tuck y McKenzie (2015), el colonizador considera las culturas indígenas como asunto de un pasado extinto, sin un lugar en el presente. El colonizador desea la tierra de los indígenas, no las personas indígenas, por lo cual "las poblaciones indígenas deben ser removidas del camino de la expansión colonial, primero vía genocidio y destrucción, y más tarde por medio de la incorporación y asimilación" (66).

El hecho de que las antiguas colonias españolas y portuguesas obtuvieran la independencia no subsanó las necesidades de los pueblos indígenas. En el caso particular de los estados-nación que surgieron en Latinoamérica, se optó por diversas vías para promover un sentido de identidad nacional. Las culturas nativas fueron succionadas dentro de un imaginario unificado por un nacionalismo creado y apoyado por las clases burguesas y las élites intelectuales, quienes se denominaron a sí mismos liberales, y que seguían viendo en Europa, y posteriormente en los Estados Unidos de América, modelos de guía hacia la modernidad, la cual tiene como base el concepto de democracia, y el cada vez más pujante capitalismo, dentro del cual la privatización de la tierra y sus recursos es parte fundamental del desarrollo (Mignolo y Walsh 2018; Pujadas 2000; Quijano 2000; Rodríguez 2006; Rosabal-Coto 2013, 2014, 2016; Tutino 2000). Los intereses y necesidades de los pueblos indígenas en Latinoamérica quedan relegados a un plano insignificante, ya que desde la conformación de los diversos estados-nación se buscó "incorporar a los sectores indígenas de la sociedad a un proyecto económico, social y cultual nacional que en la práctica niega las matrices culturales indígenas a favor de valores y visiones de las élites criollas y ladinas4, de corte occidental" (Pujadas 2000, 115).

Quijano (2000) apunta cuatro trayectorias históricas y líneas ideológicas que es posible identificar en los estados-nación en el sur global del continente. Éstas trayectorias tienen como finalidad crear sociedades en que se implanta en el imaginario colectivo una homogenización cultural basada en una identidad conformada por experiencias históricas supuestamente comunes.

La primera de estas trayectorias se refiere a un proceso de descolonización/ democratización propio de revoluciones radicales en países como Bolivia y México,

Vázquez Córdoba, Héctor Miguel. 2019. (Re)centrando las perspectivas indígenas en la educación musical en América Latina. Action, Criticism, and Theory for Music Education 18 (3): 172-99. http://doi.org/10.22176/act18.3.172 
cuyos efectos fueron paulatinamente limitados en las décadas de los sesenta y setenta. La segunda tiene que ver con países como Argentina, Chile y Uruguay, en los que se recurrió a buscar una homogeneidad racial al recibir millones de inmigrantes provenientes de Europa, lo que pretendía crear una identidad "blanca" de forma intempestiva. Una tercera tiene que ver con la búsqueda de una homogenización cultural basada en el "genocidio cultural de indios, negros y mestizos" (237). El autor destaca en este caso países como Perú, Guatemala, México, Ecuador y Bolivia. La cuarta y última se refiere a una discriminación que se da hacia las personas cuyo origen es africano, en países como Brasil, Colombia y Venezuela, al mismo tiempo que se pretende abogar por una "democracia racial", que únicamente sirve para enmascarar la discriminación que sufre la población antes mencionada.

\section{La Visión Eurocéntrica del Saber}

La cultura traída a América Latina desde Europa fue presentada como el pináculo de una evolución cultural (Rosabal-Coto 2016; Quijano 2000), concebida como "el espejo del futuro de todas las demás sociedades y culturas, como el modo avanzado de la historia de toda la especie" (Quijano 1992, 18). Las otras culturas fueron situadas como primitivas o exóticas. Esto dio paso a un discurso que abogaba por la adopción de principios que están alineados con la cultura europea, que se concibe como un modelo cultural universal al que debían aspirar las culturas no europeas (Mignolo y Walsh 2018), y que tenía como pilares la "teología cristiana, filosofía secular europea y ciencia, todas ellas conectadas con el Renacimiento” (RosabalCoto 2016, 27).

El concepto colonialidad permite explicar un patrón de poder que trasciende más allá de un dominio territorial por medios coercitivos propios del colonialismo, ya que la colonialidad da paso a una forma de dominio que se extiende a escala mundial, y que se impone en el imaginario cultural y epistemológico. Este control se apoya en la idea de raza y división de trabajo, teniendo a cierta parte de la población mundial ocupando un papel de dominadora, sobre otra que históricamente se define como dominada (Garzón 2013, 2018; Quijano 1992, 2000).

Quijano (1992) señala que una particularidad de la colonialidad es la forma de producción del conocimiento enmarcado por "la racionalidad/modernidad europea, el cual fue establecido como un paradigma universal de conocimiento" (14). El autor apunta que esta forma del saber basado en lo racional crea una separación

Vázquez Córdoba, Héctor Miguel. 2019. (Re)centrando las perspectivas indígenas en la educación musical en América Latina. Action, Criticism, and Theory for Music Education 18 (3): 172-99. http://doi.org/10.22176/act18.3.172 
entre el sujeto/individuo que se constituye a sí mismo por su capacidad de reflexión, y el objeto, que es externo al individuo y cuya función es ser estudiado y definido por el sujeto. El papel de objeto es dado a las culturas no europeas, las cuales deben ser estudiadas y definidas a través de la cultura dominante (Mignolo y Walsh 2018; Quijano 1992). A su vez, la perspectiva occidental propone el modelo científico como forma única de acceder al conocimiento, ya que el distanciar al sujeto del objeto implica que el producto resultante no estará "contaminado", y se producirá un conocimiento superior y verdadero, por lo tanto "cualquier otro conocimiento que no reúna tales estándares será considerado inferior, pre-científico, pre-moderno o tradicional" (Garzón 2013, 316). La superioridad otorgada al modelo científico habrá de demeritar otras formas de relacionarse y acceder al conocimiento. Partiendo de una visión eurocéntrica del saber, se considera como tribal, exótico o primitivo todo aquello que no parta de ella. Se le confiere, a quienes representan todo lo que no es occidental, una identidad estigmatizada, que los confina a un colectivo imaginario de ciudadanos(as) de tercera categoría, y que deben asimilar la cultura del colonizador (Devalle 2000; Giménez 2000; Quijano 2000; Thekkevallyara 2013).

La estructura de poder que surge de la colonialidad es el marco operativo sobre el cual se basa el sistema global de explotación, discriminación, distribución del capital y del trabajo (Quijano 1992). De acuerdo con Garzón (2013), la colonialidad trasciende más allá del colonialismo y el imperialismo, ya que "perdura en la era poscolonial...se proyecta en los medios de comunicación, en el sistema educativo, en el lenguaje cotidiano, etcétera, pero, sobre todo, ha sido incorporado en el habitus de los sujetos colonizados" (311-12). Lo anterior plantea un reto en identificar cuáles son los patrones aceptados como normales en la sociedad, producto de prácticas que se han hecho parte de la cotidianidad, de manera casi invisible, perpetuando la narrativa de la cultura dominante.

Parte importante del dominio de Europa occidental sobre el resto del mundo recae en el poder de la relación capital-salario, "Europa y lo europeo se constituyeron en el centro del mundo capitalista” (Quijano 2000, 208). Mientras Europa occidental se convierte en el centro mundial del flujo de capital, otras zonas geográficas (incluyendo América Latina) son explotadas tanto en sus recursos naturales como en la fuerza de trabajo de sus pobladores nativos, bajo la justificación de que los trabajadores pertenecen a una raza inferior que no merece retribución económica alguna (Mignolo y Walsh 2018; Quijano 2000). Estas relaciones de 
posesión del capital, a su vez, marcan el futuro de Latinoamérica, la cual juega un papel a nivel global de proveedora de materia prima y consumidora de conocimiento (Albán 2008).

\section{Representación del "Saber" Música y "Ser" Músico}

En el entramado que plantea la colonialidad, la música no permanece ajena a ser usada como objeto que contribuye a acentuar las diferencias entre lo que se pretende representar como forma más avanzada de cultura y el resto: las culturas no occidentales. En este sentido, la música de origen europeo, particularmente la música de arte, o clásica, es el modelo bajo el que habrán de ser observadas y analizadas el resto de la músicas, que son catalogadas como world music, categoría que congrega a todas las músicas que se analizan desde una visión eurocéntrica como diferentes a la música que representa a la cultura europea (Bradley 2012; Hess 2015, 2017). Conceptos como la escritura de la música, que simboliza la capacidad de abstracción de los sonidos y ritmos en una partitura, así como la apreciación de la música a través de procesos cognitivos, donde el ejecutante y audiencia no tienen interacción alguna durante el acto musical, son fundamentales a las relaciones con una forma "superior" de arte (Emmerson 2000; Goble 2015; Shifres y Gonnet 2015). Al ser considerada como productora de materia prima, América Latina no será referente en el ámbito de la música culta, por lo que será "necesario" importar desde Europa formas musicales que contribuyan a proveer de cultura a los territorios conquistados (Shifres y Gonnet 2015).

$\mathrm{Al}$ consolidarse los procesos de independencia en Latinoamérica, la Iglesia Católica, que históricamente había provisto de instrucción musical formal, fue remplazada por los conservatorios (Shifres y Gonnet 2015; Sturman 2016). En estas instituciones, se reproduce un modelo de instrucción alineado con la separación entre sujeto y objeto, promovido desde la colonialidad, donde el sujeto, solamente mediante su esfuerzo individual, puede comprender al objeto (música). Ello contribuye a un sistema de competencia, en el cual la obtención de saberes se vuelve una tarea personal que pondera al individuo sobre el grupo. Esto es coherente con un modelo capitalista en el que la música se concibe como un producto para ser explotado (Shifres y Gonnet 2015). De acuerdo a los antes mencionados autores, el modelo conservatorio "condujo el proceso de secularización de la educación musical, y concomitantemente de la especialización (de la profesión) musical” (58). A

Vázquez Córdoba, Héctor Miguel. 2019. (Re)centrando las perspectivas indígenas en la educación musical en América Latina. Action, Criticism, and Theory for Music Education 18 (3): 172-99. http://doi.org/10.22176/act18.3.172 
partir de los estándares proporcionados por los conservatorios, como instituciones que representan la cultura dominante, será posible implantar una forma "superior" de relacionarse con la música, y con ello desestimar formas de interacción con la música que no estén alineadas con los parámetros que dicho ente demarque.

$\mathrm{Al}$ ser el modelo conservatorio el regulador de las interacciones que se dan con y a través de la música, a esta institución también se le confiere el poder de catalogar (separar) a los músicos (provistos de una instrucción formal e institucional) de los no músicos. Las músicas que no son producidas ni reproducidas dentro del modelo conservatorio pasan a formar parte de una periferia musical, y con ello las personas que son sus portadoras. La música como objeto de arte crea una brecha entre quiénes serán reconocidos como músicos (alfabetizados) y los no músicos (no alfabetizados), lo cual restringe el quehacer social del músico a un papel de intérprete musical para la crítica experta (limitada a las personas con cierto capital cultural), y dejando a los "otros" músicos prácticas que no son valoradas por carecer de un aval académico que valide la importancia de tal quehacer musical en contextos más informales y prácticos (Bourdieu 1984; Ruddock 2017; Shifres y Gonnet 2015). Lo anterior, conduce a cuestionar el papel de la educación musical como vía para la enseñanza de la música como un "objeto" digno de ser apreciado meramente desde un enfoque estético, informado por una visión eurocentrista-universalista. En cambio, es pertinente considerar la educación musical como oportunidad para relacionarse con la música más allá de una visión abstracta del saber, lo cual requiere el contacto directo con quienes producen dichas manifestaciones sonoras, entendiendo los contextos y cosmovisiones donde éstos se originan (Bradley 2012; Goble 2010, 2015); de otra forma se corre el riesgo de que "en lugar de entender la música en sus propios términos, el alumnado pueda malinterpretar el significado de la letra de la canción o encontrar algo acerca de la música que pueda ser desagradable, objetable, aburrido, o incluso ridículo, porque representa algo contrario a sus propios valores" (Goble 2010, 5).

Para Bradley (2012), considerar el aprecio de la música desde características meramente estéticas propicia una división entre la música occidental y el resto de las músicas, ya que la primera se considera superior y representa los valores estéticos y de sofisticación que son valorados desde una perspectiva eurocéntrica. Lo anterior urge a encontrar formas de romper un colonialismo ideológico que excluye formas de entender la música desde una perspectiva egocéntrica (Shifres y

Vázquez Córdoba, Héctor Miguel. 2019. (Re)centrando las perspectivas indígenas en la educación musical en América Latina. Action, Criticism, and Theory for Music Education 18 (3): 172-99. http://doi.org/10.22176/act18.3.172 
Gonnet 2015); este colonialismo ideológico discrimina y menosprecia formas específicas de relacionarse con y a través de la música.

\section{La Importancia de Volver la Mirada hacia las Culturas Indígenas}

En 2007 se aprobó la Declaración de las Naciones Unidas sobre los Pueblos Indígenas (Organización de las Naciones Unidas 2008). Este documento contiene 46 artículos que hacen énfasis en las necesidades básicas de los pueblos indígenas en busca del respeto por sus costumbres e identidades, ya que éstas han sido violentadas por siglos de colonialismo. En este trabajo, me referiré al artículo 15 sección 1, el cual señala que "los pueblos Indígenas tienen derecho a que la dignidad y diversidad de sus culturas, tradiciones, historias y aspiraciones queden debidamente reflejadas en la educación y la información pública” (7). Es particularmente importante señalar que la cultura de los pueblos indígenas debe hacerse patente en la educación pública, manteniendo y promoviendo sus usos y costumbres. Esto sirve para crear espacios para el diálogo de cómo se plantearía promover esa diversidad cultural dentro de la educación, y particularmente en la educación musical. Para ello, es pertinente mirar a las culturas locales y quiénes son las personas herederas de los conocimientos ancestrales, a fin de establecer relaciones de colaboración que incluyan espacios de aprendizaje de su música y cosmovisión.

En cuanto al ámbito particular de la música, es crucial definir qué es lo que se entiende por música indígena en diversos contextos de América Latina. Es importante señalar que lo aquí expuesto no abarca la totalidad de los contextos de las músicas indígenas en el sur global del continente. Sin embargo, la consideración de algunos ejemplos provenientes de diversos estudios sirve para la discusión del tema.

La palabra "música" es un término impuesto a las personas nativas del continente americano (Sturman 2016). De ahí que la música no sea entendida por las culturas indígenas como un acto meramente de entretenimiento, sino conectado a rituales en los que la música es un canal para conectarse con energías y divinidades, y que se liga estrechamente a la danza, donde el quehacer musical es parte de un entramado colectivo y social (Bermúdez 2010; Martínez 2002; Sturman 2016; Pacheco 2016). Si bien la colonización impacta directamente en las formas en que las personas se relacionan a través de la música, diversas características continúan vigentes en las prácticas musicales ligadas a raíces indígenas. El mestizaje entre

Vázquez Córdoba, Héctor Miguel. 2019. (Re)centrando las perspectivas indígenas en la educación musical en América Latina. Action, Criticism, and Theory for Music Education 18 (3): 172-99. http://doi.org/10.22176/act18.3.172 
europeos e indígenas, así como la enseñanza y uso de instrumentos de origen europeo, dieron paso a que las poblaciones indígenas adaptaran y adoptaran diversos instrumentos, a fin de conservar particularidades de las músicas y culturas locales, dentro de una nueva realidad impuesta por la colonización (Bermúdez 2010; Sturman 2016). A continuación, se presentan dos casos en los cuales se discute la música indígena, tanto en la parte norte, como en la sur de América Latina. Estos ejemplos abordan el tema de la representación "auténtica" de las culturas indígenas.

Martínez (2002) analiza la situación de la música Mapuche en Chile. El principal argumento en su análisis es la lucha entre la representación de la cultura y la reproducción de la cultura. La representación-comenta el autor-, está basada en una expectativa, tanto al interior de una parte de la cultura Mapuche, como de la visión mestiza dominante de lo que debe ser el Mapuche, ya que salir de los parámetros de lo que el Mapuche debe ser, lo confina a no ser autentico. La cultura mestiza espera una representación folclórica de los rasgos culturales que definen una mapuchidad basada en la espectacularización, lo que constituye "una nueva forma de dependencia respecto de la cultura hegemónica: al afirmarse en forma exclusiva, estas agrupaciones crean un paradigma de "lo Mapuche" al cual todos los individuos de la agrupación deben conformarse" (32). El autor hace un llamado a reflexionar acerca de la trascendencia e importancia de mantener vigentes las motivaciones de los ritos y ceremonias, por encima de aspectos meramente superficiales. Éstas favorecen la reproducción de la cultura "a través de la mantención dialéctica de sus anclajes significativo: como modo de hacer, decir y sentirse mapuche, más que por la exhibición de particulares signos de una mapuchidad cristalizada" (32). Lo anterior, es una muestra clara de que las culturas indígenas no son estáticas; la imposición de dogmas sobre auténtico y tradicional tiene que ver más con factores externos provenientes de la cultura dominante, de lo que se espera de un "auténtico" Mapuche.

Sturman (2016) plantea que en el contexto particular de México, la música indígena no es aquella que se escucha en las zonas arqueológicas, que en cierta forma romantiza un ideal de lo indígena. En cambio, la música de raíces indígenas está presente en diversos espacios de la vida pública, donde los músicos, además de ser especialistas en el quehacer musical, también desempeñan otras actividades. La autora plantea que en México los grupos indígenas lograron conservar sus herencias y tradiciones culturales mediante la adopción de prácticas cristianas, lo que 
les permitió de manera sincrética mantener vigentes aspectos propios de su cultura. "[P]arece irónico que los pueblos indígenas se apropiaron de la victoria de la conversión, adaptando los formatos cristianos y europeos para retener ciertas creencias religiosas nativas y prácticas culturales a fin de mantener control para crear sus propias interpretaciones" (95). Esto se refleja particularmente en la adopción y adaptación de ciertos instrumentos y formas musicales que se originan en Europa. Sturman hace particular énfasis en ejemplos como el de los Mixes en el estado de Oaxaca, donde las bandas de alientos formados por indígenas Mixes, alguna vez utilizadas para propósitos meramente religiosos, eventualmente se transformaron en entes ligados estrechamente al entramado social de los pueblos de la región. Éstas se han convertido en instituciones centrales de liderazgo y representación en las comunidades.

\section{Descentrando Formas Hegemónicas del Saber}

Para poner al centro las necesidades de los pueblos indígenas y promover sus culturas ancestrales por medio de la educación musical, quiero hacer referencia a lo que Sandra Styres (2017) propone en su libro Pathways for remembering and recognizing Indigenous thought in education (Caminos para recordar y reconocer el pensamiento indígena en educación). La autora arroja luz sobre la problemática que conlleva establecer principios educativos que reconocen la herencia indígena en un sistema diseñado para perpetuar las relaciones de poder colonial, y también analiza las posibilidades de transformar la práctica educativa para colocar las necesidades de los pueblos indígenas en el centro de la conversación, acorde con los fines de la Declaración de las Naciones Unidas sobre los Pueblos Indígenas.

Styres analiza el papel que ocupan los saberes indígenas con respecto a los conceptos colonización y descolonización. Para la autora, el colonialismo tiene que ver con la conquista de la tierra y de los bienes de otras personas. Éste redefine el papel del conquistado dentro en la estructura social que resulta del proceso de colonización que incluye la explotación y venta de los recursos naturales y humanos. Para la autora, el término descolonizar (decolonizing) se refiere a un proceso activo en el que la persona que sufre las consecuencias de la colonización busca liberarse del yugo colonial, a fin de conseguir su independencia o soberanía; en tanto, descolonización (decolonization) se puede entender como punto de llegada o resultado del proceso de descolonizar.

Vázquez Córdoba, Héctor Miguel. 2019. (Re)centrando las perspectivas indígenas en la educación musical en América Latina. Action, Criticism, and Theory for Music Education 18 (3): 172-99. http://doi.org/10.22176/act18.3.172 
Styres analiza tres posibles caminos para lograr la descolonización. En el primero de los casos, el colonizador sale de los territorios ocupados y se lleva todo el aparato que promueve la continuación de relaciones coloniales. En la segunda opción, el colonizador concede la soberanía política y económica a los grupos colonizados, sin que esto conlleve la salida del colonizador. Una tercera opción requiere un acto de resistencia al poder del colonizador, lo que conlleva que el colonizado tome acciones-en muchos casos, violentas-en busca de su legítima libertad, pasando de ser oprimido, a convertirse en opresor. Styres también reflexiona sobre un tema también tratado por Smith (2012) y Kovach (2009): la posibilidad de realmente hablar de un estatus poscolonial cuando las relaciones coloniales rodean diversos ámbitos de la vida de los pueblos indígenas. Styres acuña lo dicho por Sykes (citado por Smith 2012): "[P]ostcolonial solo puede significar una cosa: que el colonizador se ha ido"(101). Styres (2017) advierte que no es posible hablar de un "post" cuando las relaciones coloniales siguen vigentes y se adaptan a nuevos contextos.

Styres considera necesario proveer un marco teórico de referencia centrado en la cosmovisión y necesidades de los pueblos indígenas, no buscando una relación directa con la visión que pone al colonizador como mediador que define y da valor a los saberes que surgen desde los pueblos indígenas y sus cosmovisiones: "[D]escolonizar, aun cuando en principio es deseado, es un proceso que por su misma naturaleza está continuamente (re)centrando las relaciones coloniales-es el hámster atrapado en la interminable rueda de la repetición y replicación" (35).

Desde la perspectiva de esta autora, es pertinente considerar una filosofía centrada en la Tierra (Land-centred) que identifica, y a la vez "(de)centra las relaciones coloniales al privilegiar y (re)centrar el pensamiento indígena enfocándose en la filosofía de lethi'nihsténha Ohwentsia'kékha (Tierra)" (123). La filosofía basada en la Tierra, como concepto filosófico y teórico, comprende "la circularidad, las relaciones, el lenguaje, las historias y la experiencia como modelo central para interpretar el sentido de la realidad" (38). Desde esta visión, el individuo no es un ente aislado. La circularidad comprende la interconectividad que éste tiene con el cosmos, la tierra, con lo humano y lo no humano. La oralidad, como forma de transmitir el conocimiento, es parte fundamental en las tradiciones indígenas, ya que pone al centro los pensamientos y formas de entender el mundo de quienes reproducen la cultura: "[L]as historias no pueden ser separadas de la tierra en las cuales éstas ocurren, o de las relaciones de interconexión que se forman a partir de 
éstas" (39). A través de las historias orales, los pueblos indígenas explican cómo fueron creados en la tierra y de la tierra, contrastando con las historias del colonizador, que relatan su llegada a un territorio (Styres 2017; Tuck y McKenzie 2015). De esto se desprende una particularidad importante en el concepto de tierra (lugar): Se opone al concepto de propiedad, acuñado por la visión colonizadora, donde la relación ser humano-tierra está "redefinida/reducida a su propiedad. Cuando la tierra es reinterpretada como propiedad, el lugar se convierte en intercambiable, vendible y posible de robar" (Tuck y McKenzie 2015, 64). Donde la visión occidental define un espacio físico (p.e., rio, montaña o bosque) como una propiedad que debe ser explotada para generar lucro, las culturas indígenas ven aquellos lugares donde ancestralmente han vivido y convivido, y que representan sus historias y ceremonias. Styres (2017) ejemplifica lo anterior, al señalar que cuando una persona indígena pregunta a otra que de cuál clan proviene, está haciendo alusión al vocablo en inglés clay (que se traduce como arcilla o barro), lo que implica preguntar de cuál tierra proviene, con todas las connotaciones que el término tierra conlleva. De ahí la importancia de las historias y la tradición oral para (re)centrar los conocimientos en un lugar particular, el cual no es intercambiable o reemplazable por una extensión de tierra que contenga exactamente las mismas proporciones. Directamente ligado a las historias, el lenguaje constituye un agente importante del conocimiento en las culturas indígenas, ya que actúa como mecanismo "capaz de expresar divergentes formas de entender el mundo... [E]l lenguaje es poderoso porque nos recuerda quiénes somos, ya que está fuertemente relacionado con la identidad personal y cultural" (59).

De acuerdo con Wilson (2008), el conocimiento "no puede ser poseído o descubierto, ya que éste solo puede ser develado mediante las relaciones que le dan una forma visible" (127). Por lo tanto, desde la perspectiva indígena, el conocimiento o la verdad no puede ser algo aislado, pues la realidad está basada "en las relaciones que uno tiene con la verdad" (73). Es así como la construcción del conocimiento debe entenderse como un proceso social y no como un hecho ajeno al individuo, y basado únicamente en el intelecto, sino que también debe tomar en cuenta las emociones, la intuición, la praxis, y la espiritualidad (Chilisa 2012; Kovach 2009; Styres 2017; Wilson 2008). Una de las formas de honrar el conocimiento como algo que no se posee de forma individual, es mediante nombrar a la persona o personas de quien o quienes se ha aprendido, y su vez, transmitir el conocimiento siendo lo más fiel posible a las formas en que éste fue recibido. Con

Vázquez Córdoba, Héctor Miguel. 2019. (Re)centrando las perspectivas indígenas en la educación musical en América Latina. Action, Criticism, and Theory for Music Education 18 (3): 172-99. http://doi.org/10.22176/act18.3.172 
esto, desde una perspectiva indígena, se asegura la credibilidad de lo que se enseña (Chilisa 2012; Kovach 2009; Wilson 2008).

Styres (2017) apunta que los conocimientos basados en filosofías indígenas no representan un pasado olvidado, sino que siguen vigentes, adaptándose a las realidades contemporáneas. La autora considera que la autenticidad en las formas del saber tiene como base conceptos que van más allá de una temporalidad o espacio (sea rural o urbano), ya que los conocimientos, al ser transmitidos, deben ser "emocionalmente y relacionalmente apropiados, significativamente relevantes, con un propósito y conscientemente respetuosos y éticos" (84). El plantear aspectos básicos y fundamentales que guíen los procesos de transmisión del conocimiento permite también flexibilidad en las formas de encaminar los aprendizajes. Lo anterior favorece que los conocimientos no sean encapsulados en formas estáticas que contribuyan a una folclorización de lo que deben representar los saberes indígenas.

\section{Filosofía Centrada en la Tierra, como Propuesta Educativa}

Styres (2017) reflexiona sobre la educación occidental, la cual tiene como uno de sus objetivos "preparar a los(as) estudiantes para cumplir su función como ciudadanos(as)" (97). La escuela tiene como cometido promover un cúmulo de creencias que respaldan una verdad única, que se vuelca en una ideología nacionalista. Ésta sigue la línea racionalista Newtoniana-Cartesiana que justifica "la industrialización y comercialización de la educación ... que reduce los procesos de aprendizaje a una serie de factores o elementos que conducen hacia la universalidad de resultados predeterminados-cualquier otra forma de saber es considerada irrelevante" (111).

Styres enfatiza constantemente que el modelo basado en la Tierra no busca competir o ser reconocido como válido por la perspectiva eurocéntrica, y reconoce los retos que esto acarrea en los ámbitos académicos, ya que en dichos ámbitos se avala los saberes considerados verdaderos. Un punto trascendental en su propuesta es la creación de espacios éticos (Ermine 2007), ya que estos permiten el diálogo entre dos filosofías de vida distintas (en este caso la indígena y la occidental), por lo cual es posible hallar un espacio neutral donde "las relaciones de poder dejen de existir y que el continuo diálogo provea una manera de confrontar y resolver el conflicto" (Styres 2017, 28). Además, agrega, que en el ámbito educativo ello implica que "dos sistemas de saberes, distintos pero igualitarios, coexisten"

Vázquez Córdoba, Héctor Miguel. 2019. (Re)centrando las perspectivas indígenas en la educación musical en América Latina. Action, Criticism, and Theory for Music Education 18 (3): 172-99. http://doi.org/10.22176/act18.3.172 
(137). Para esto, la autora hace un llamado a crear espacios éticos en la educación, en los que tanto docentes como estudiantes puedan establecer un diálogo que respete y promueva equidad entre diversas formas del saber, y relacionarse con éste.

La propuesta de la autora es visionar una educación desde la perspectiva indígena, basada en la idea de que las personas, las culturas y su visión del mundo, son dinámicas, y en que la interacción con el mundo natural (Tierra) y espiritual son necesarias para vivir en armonía. El proceso educativo no se da de forma aislada, sino que se invita a aprender con la comunidad, en una práctica activa acorde con el contexto social, en el que las personas mayores (elders) tienen un rol importante y de modelo para los(as) jóvenes indígenas. Todo esto involucra las historias, mitos, leyendas, ceremonias y experiencias vividas, contextualizando entonces el proceso educativo.

\section{Propuesta Aplicada al Contexto de la Educación Musical}

Desde la perspectiva de una filosofía educativa basada en la Tierra, los resultados o fines no son lo más importante, sino que se valora principalmente el proceso. Esto marca una diferencia en relación con las directrices que los sistemas educativos siguen actualmente. Principalmente, porque los sistemas educativos a nivel mundial se basan en estipulaciones de diversos organismos internacionales, como la Organización para la Cooperación y el Desarrollo Económico, el Banco Mundial, y el Fondo Monetario Internacional (García 2012). Lo anterior, bajo el argumento de promover una estandarización en los saberes que esté acorde con las necesidades de un mundo globalizado; sin embargo, este argumento no reconoce los contextos sociales, políticos y económicos que existen en los diversos países donde se llevan a cabo pruebas estandarizadas de conocimientos como la Programme for International Student Assessment (PISA). El favorecer una visión hegemónica impuesta sobre el valor de un cierto tipo de conocimiento se vuelve la excusa perfecta para dejar de lado otras formas del saber, particularmente las que representan aquellas cosmovisiones que han sido históricamente menospreciadas y estigmatizadas.

Si los sistemas educativos tienen como principal objetivo que el alumnado obtenga mejores puntajes en pruebas estandarizadas, favorecen el resultado sobre el proceso. En cambio, si el proceso es parte fundamental del acto educativo, entonces el cómo se llega a los resultados se convierte en el eje para transitar de un

Vázquez Córdoba, Héctor Miguel. 2019. (Re)centrando las perspectivas indígenas en la educación musical en América Latina. Action, Criticism, and Theory for Music Education 18 (3): 172-99. http://doi.org/10.22176/act18.3.172 
proceso de instrucción a uno de educación. Bowman (2002) es claro al marcar una diferencia entre instrucción y educación. Por un lado, distingue a la instrucción como el proceso para dominar ciertas habilidades con el fin de actuar en un contexto determinado, por lo cual el cúmulo de las habilidades no son necesariamente transferibles a otros ámbitos de la vida. En cambio, el proceso educativo no solamente equipa a las personas para ejecutar diversas tareas, sino también para que éstas "tengan la capacidad de cuestionar, de mirar a las cosas desde diversas perspectivas, y que sean conscientes de los posibles prejuicios e imperfecciones de esas perspectivas, incluyendo las propias" (66).

El plantear una educación basada en la filosofía centrada en la Tierra, en la educación musical, va más allá de desarrollar las habilidades para ejecutar la música indígena, por lo cual es fundamental no limitarse solamente al uso de instrumentos y repertorios (o adaptaciones) de música de raíces indígenas. Aunque ello en cierta forma promueva las culturas locales, queda en representaciones triviales que no contribuyen a un cambio de fondo que atienda la necesidad de promover las culturas indígenas a la par de la cultura dominante (Bradley 2012; Hess 2015; 2017; Locke y Prentice 2016). En cambio, la filosofía centrada en la Tierra es una oportunidad para adentrase en una forma diferente de ver el mundo, y con ello generar disonancias que inciten nuevas preguntas, que cuestionen los mismos principios de todo aquello que hemos dado por sentado y por válido, enfrentando los prejuicios propios, esos que han hecho que en sociedad marginemos a los pueblos indígenas.

Considerar una filosofía centrada en la Tierra (Land-centred), desde las formas originarias de la producción y transmisión de los saberes de las culturas indígenas, ofrece una oportunidad para que éstas sean valoradas por sí mismas, sin la necesidad de buscar una justificación o validación desde la óptica occidental. Esto abre espacios para que la enseñanza de música que tiene raíces indígenas sea considerada por sus propios méritos, a fin de ser parte fundamental dentro de la educación musical.

La propuesta de incorporar las cosmovisiones de los pueblos indígenas a través de la educación musical no es exclusiva de un nivel escolar o modelo educativo en particular. Esta propuesta es más bien un llamado a los(as) educadores(as) de todos los niveles y de diversas disciplinas a reflexionar sobre la importancia que pudiera tener incluir las perspectivas de las culturas locales en su práctica docente. Los principios y las razones aquí expuestas del uso de la música como medio para

Vázquez Córdoba, Héctor Miguel. 2019. (Re)centrando las perspectivas indígenas en la educación musical en América Latina. Action, Criticism, and Theory for Music Education 18 (3): 172-99. http://doi.org/10.22176/act18.3.172 
adentrase en la cosmovisión de los pueblos originarios es solo uno de diversos medios que pueden usarse para aprender de manera significativa las culturas locales. Se considera importante el uso de la música como medio para el conocimiento de los saberes indígenas, ya que se vislumbra relacional y emocionalmente apropiada, significativa, relevante y con un propósito de promoción ética de la cultura (Styres 2017). En este sentido, es crucial prever el establecimiento de colaboraciones con los individuos portadores de la cultura, en particular con músicos y personas mayores que conocen a fondo los saberes y tradiciones ligadas a la práctica musical, a fin de procurar experiencias significativas de aprendizaje (Archibald 2011; Locke y Prentice 2016). Es importante recordar que las culturas indígenas están vivas y que son parte de contextos actuales (Martínez 2002; Styres 2017). El respeto a sus principios no se basa solamente en aspectos meramente estéticos que folclorizan y fosilizan prácticas que representan una forma ideal de la cultura local. Ello deja de lado los principios básicos que pueden ser menos evidentes a la hora de la representación escénica, y que tienen que ver con conceptos más profundos, como el modo de hacer, decir y sentir que son parte de la cultura (Martínez 2002). Ante ello, es primordial estar en contacto con quienes son portadores(as) de la cultura, para que nos guíen con base en sus propias experiencias, a fin de no asumir, desde una mirada etnocentrista, qué es lo que constituye una experiencia auténtica. El asumir desde una visión etnocentrista qué es auténtico, y qué no, contribuirá a una imagen de lo "ideal", en detrimento de la autodeterminación de los pueblos indígenas, de cómo quieren ser vistos y de los principios medulares de sus culturas.

La incorporación de principios que sean afines a las culturas locales en la educación musical puede contribuir a alcanzar lo ya establecido en la Declaración de las Naciones Unidas sobre los Pueblos Indígenas, en particular el artículo 15, sección 1, sobre el derecho que tienen las culturas de los pueblos indígenas a ser representadas en la educación y la información pública. Como se comentó previamente-y me gustaría enfatizar-esto implica ir más allá de la adopción de instrumentos y repertorios. Conviene, en cambio, que la educación musical vaya más allá de una mera instrucción musical, y se convierta en un medio para valorar las culturas locales, particularmente cuando ese valor se basa en las cosmovisiones y formas del saber de los pueblos indígenas.

Vázquez Córdoba, Héctor Miguel. 2019. (Re)centrando las perspectivas indígenas en la educación musical en América Latina. Action, Criticism, and Theory for Music Education 18 (3): 172-99. http://doi.org/10.22176/act18.3.172 


\section{Posibles Retos para la Implementación de la Filosofía Centrada en la Tierra en la Educación Musical, y Caminos para Iniciar su Puesta en Marcha}

Soy consciente que el plantear la adopción de una filosofía basada en los principios de las culturas indígenas podría generar resistencias, tanto a nivel social como en el ámbito educativo, ya que, como ha sido discutido a lo largo de este texto, las cosmovisiones indígenas han sido sistémicamente ignoradas. Ante esto, parece una tarea titánica implementar acciones concretas para dar cabida a una forma paralela del saber, y particularmente del quehacer en la educación musical; por lo tanto considero pertinente partir desde la identificación de causas internas y externas que pueden afectar la puesta en marcha de una filosofía centrada en la Tierra, en la educación musical, particularmente en el contexto latinoamericano.

\section{Causas internas}

Las causas internas son aquellas en las que el(la) educador(a) musical decida no adoptar un enfoque que, en cierta forma, contrasta con la manera en que concibe el acto musical y su educación.

1. Muchos(as) educadores(as) musicales se han formado bajo un sistema educativo que prepondera la transmisión de conocimientos por medio de la teoría asociada a la música clásica, como único medio válido para relacionarse con la música. Por lo tanto, cualquier otro enfoque que no esté dentro de los parámetros asociados a la música clásica no es considerado por los(las) educadores(as), ya que esto va en contra de la concepción propia de lo que debe ser la correcta aproximación al quehacer musical.

2. Implementar un nuevo enfoque conlleva que la persona que educa musicalmente deje de lado una zona de confort. Requiere asumir riesgos, ya que será necesario replantear los contenidos y como éstos se podrán aplicar, mientras que se es consciente de que una mera inclusión de instrumentos y repertorios de músicas de raíces indígenas solo promueve una trivialización. Idealmente, los cambios pueden involucrar una colaboración cercana con los individuos portadores de las culturas indígenas, a fin de contextualizar los saberes musicales dentro de las cosmovisiones de quienes éstas representan.

Vázquez Córdoba, Héctor Miguel. 2019. (Re)centrando las perspectivas indígenas en la educación musical en América Latina. Action, Criticism, and Theory for Music Education 18 (3): 172-99. http://doi.org/10.22176/act18.3.172 
3. Los(as) educadores(as) podrían temer representar de forma inadecuada los conocimientos asociados a las culturas indígenas, o bien, hacer un mal uso de ciertos conocimientos que guardan un protocolo especial para su reproducción.

\section{Causas externas}

Estas causas tienen que ver con aspectos que están inmersos en el contexto social, así como en la estructura de los sistemas educativos. Estos dos ámbitos pueden inhibir o resistir la puesta en marcha de una filosofía educativa que contrasta con lo que la sociedad y los sistemas educativos consideran como válido e importante. En estos casos, los(las) educadores(as) musicales pueden encontrar dificultad para poner en marcha iniciativas dentro del sistema educativo.

1. La colonialidad está presente en el día a día en Latinoamérica, ya que como expresa Garzón (2013), está incorporada en el habitus de la sociedad. Por lo tanto es "normal" para los(as) colonizados(as) que las perspectivas indígenas sean menospreciadas e ignoradas. Tomando esto como punto de partida, es posible prever que la sociedad en general no vea con buenos ojos el que las perspectivas de los grupos indígenas sean adoptadas dentro del sistema educativo.

2. Faltan espacios para poner en práctica proyectos significativos que atiendan los saberes de las culturas locales, en parte por el diseño curricular emitido por los sistemas educativos, los cuales preponderan cumplir los objetivos trazados por organismos internacionales. Esto conlleva una falta de apoyo por parte de la estructura de los organismos educativos a nivel administrativo, operativo y económico. A esto se suma la posible resistencia por parte de las autoridades educativas, debido a que en el imaginario colectivo de muchos países lo asociado a culturas indígenas es visto como carente de valor científico suficiente para ser adoptado dentro de los planteles educativos.

\section{Camino hacia la puesta en marcha de la filosofia educativa centrada en la Tierra}

Una vez presentadas posibles causas internas y externas que inhiben la puesta en marcha de una filosofía educativa basada en los saberes indígenas, es pertinente hacerse estas preguntas: ¿Por qué es importante considerar la filosofía educativa centrada en la Tierra? ¿Por qué, como educadores(as) musicales, molestarse en

Vázquez Córdoba, Héctor Miguel. 2019. (Re)centrando las perspectivas indígenas en la educación musical en América Latina. Action, Criticism, and Theory for Music Education 18 (3): 172-99. http://doi.org/10.22176/act18.3.172 
poner en marcha acciones que muy posiblemente encontrarán resistencia tanto dentro como fuera de los centros educativos? Las respuestas a estas interrogantes tendrán distintos enfoques, dependiendo la historia personal de quien las contesta y del contexto desde donde lo haga. Considero que es necesario reivindicar los saberes de las culturas locales a través de la educación musical a fin de contribuir en el respeto y aprecio de las culturas y sus portadores. Fallar a esto contribuirá a la ya larga lista de situaciones de discriminación que sufren las culturas locales y sus portadores en el día a día. Esto va más allá de cualquier concepto abstracto: solo basta caminar por las calles en las grandes ciudades o por muchas de las comunidades rurales para darse cuenta de la situación precaria en que muchas personas indígenas viven, situaciones en las cuales somos indolentes como sociedad, ya que preferimos mirar hacia otro lado. Muchos(as) indígenas se desplazan hacías las ciudades porque no hay forma de sustentar a sus familias, ya que las actividades productivas (particularmente la agricultura), a las que históricamente han estado ligadas, cada vez están más dominadas por multinacionales que gracias a la sobreexplotación de la tierra generan mayor cantidad de producto a un precio menor, lo cual hace cada vez menos posible coexistir con éstas. A su vez, otras personas son desplazadas de sus territorios ancestrales, ya que se descubre en el subsuelo materiales que son atractivos para las compañías mineras, particularmente para las multinacionales que pueden causar destrucción y contaminación que en los países de origen de estas compañías no serían permitidos, pero bueno, "Estamos en Latinoamérica, ¿qué importa?”, dirían muchos. Promover el aprecio de las culturas locales a través de la educación musical es una posibilidad para crear empatía con aquellos que nos ha dicho son los "otros", cuando en verdad somos de los mismos. Quizás a través de la educación musical podamos entender una forma de ver el mundo que nos ha sido negada porque no conviene a los intereses políticos y económicos de una minoría que sigue viendo a Latinoamérica como simple proveedora de materia prima e importadora de cultura.

Styres (2017) señala que es "posible hablar y escribir con cierto grado de certeza solo desde la posición de quienes somos y en relación a lo que sabemos" (7). Partiendo de esto, tomo el caso de México para ejemplificar el porqué de la pertinencia de poner en marcha una filosofía educativa que tome como base los saberes de los pueblos indígenas, así como acciones que permitan iniciar este proceso. Soy consciente que México, en sí mismo, tiene diversas realidades en las distintas regiones geográficas; sin embargo, este país tiene similitudes y diferencias con otros 
países de Latinoamérica, por lo cual es imposible generalizar lo aquí planteado. A pesar de ello, espero que nos provea de un contexto para la discusión.

Veintiséis millones de personas en México se consideran indígenas, es decir, el 21.5\% del total de la población de este país (CONAPO 2015). El hecho de contar con una densidad alta de personas que se identifican como indígenas debería ser razón suficiente para que desde las estructuras gubernamentales se considerara elemental el fomentar el conocimiento de las culturas locales. Sin embargo, el contenido "obligatorio" que trata la temática indígena es escaso (por decir lo menos) en la propuesta curricular vigente a nivel nacional, emitida por la Secretaría de Educación Pública (SEP) de México (SEP 2016). La SEP busca atender a la población indígena en escuelas que son diseñadas para esta población, particularmente cubriendo las necesidades bilingües, pero a su vez las escuelas indígenas no cuentan con suficientes profesores capacitados que conozcan las lenguas indígenas (SEP 2017). Lo antes señalado pone en contexto que las perspectivas indígenas no son una prioridad en el sistema educativo mexicano, ya que se crean escuelas especiales para la población indígena, con lo cual se segmenta a esta parte de la población.

Por otro lado, la propuesta curricular a nivel nacional considera escasas secciones dedicadas a temáticas indígenas, en los cuales los contenidos se relacionan con el estudio de las culturas indígenas como componente de la historia (estudio del pasado), o bien poniendo en un mismo apartado temáticas indígenas y migrantes (SEP 2016), lo cual evidencia una falta de reconocimiento hacia los pueblos indígenas que han vivido por cientos de años en el territorio que ahora es México. Una de las formas sugeridas para incluir la música de raíces indígenas en el contexto educativo mexicano, es hacer uso del componente autonomía curricular, parte de la propuesta curricular que actualmente usa la SEP (Vázquez 2017). Si bien dentro de este componente no se considera directamente el uso de música de raíces indígenas, si ofrece cierta flexibilidad para poner en marcha proyectos que sean relevantes para las escuelas. En este sentido, es trascendente el papel de los(as) educadores(as) musicales para proponer en sus centros educativos proyectos relevante para el estudiantado, donde la música sirva un doble propósito: desarrollar habilidades musicales particulares y el conocimiento y aprecio de las culturas locales. Esto requiere un compromiso del centro educativo para aprobar el uso de música de raíces indígenas como medio para el aprendizaje de las culturas indígenas dentro del componente autonomía curricular.

Vázquez Córdoba, Héctor Miguel. 2019. (Re)centrando las perspectivas indígenas en la educación musical en América Latina. Action, Criticism, and Theory for Music Education 18 (3): 172-99. http://doi.org/10.22176/act18.3.172 
Llevar a cabo un cambio estructural a nivel nacional es ciertamente complejo; por lo tanto, es necesario que los(as) educadores(as) musicales lleven a cabo colaboraciones desde contextos locales, constituyéndose en enlaces entre las culturas locales y quienes las portan, a fin de generar un movimiento que surja desde la base misma de la sociedad.

En mi experiencia, me he encontrado con personas que realizan talleres para mantener vigentes las tradiciones indígenas en diversos pueblos y ciudades en México; sin embargo, me han informado que existe una resistencia por parte de algunos centros educativos para que las prácticas que se dan en estos talleres sean implementadas en las escuelas. Esto, debido a que directivos y maestros(as) consideran que estos saberes pertenecen "a la calle", por lo cual no se logra crear ese enlace entre portadores(as) de las culturas y los centros educativos. Estas actitudes de resistencia impiden el establecimiento de un vínculo entre personas portadoras de cultura y las instituciones educativas.

El primer paso para generar un cambio es que los(as) educadores(as) musicales estén en disposición de considerar el uso de música de raíces indígenas en su práctica educativa. Esto requiere que el profesorado contemple otras formas de relacionarse con la música que posiblemente sean distintas a la forma en la cual él o ella hayan sido educados. El siguiente paso será buscar influir dentro del centro educativo con otros profesores, directivos y padres de familia. En este caso, los(as) educadores(as) musicales pueden ser pieza clave para generar los espacios éticos que contribuyan a que los saberes de las culturas locales sean presentados dentro de los centros educativos. Los(as) educadores(as) musicales se vuelven aliados(as) de los portadores de las culturas locales para invitarles a sus aulas para que compartan con el estudiantado sus cosmovisiones a través del quehacer musical. Esto conlleva establecer una relación directa con quienes son los(as) portadores(as) de la cultura, a fin de planear en conjunto cuales serían las formas de presentar los saberes, de tal manera que sean entendidos dentro de la cosmovisión de las culturas indígenas.

\section{Consideraciones Finales}

Poner al centro de las necesidades de los pueblos indígenas es una responsabilidad que debe ser compartida por diversos sectores de la sociedad, siendo los sistemas educativos parte importante para llevar a la práctica lo expresado en la

Vázquez Córdoba, Héctor Miguel. 2019. (Re)centrando las perspectivas indígenas en la educación musical en América Latina. Action, Criticism, and Theory for Music Education 18 (3): 172-99. http://doi.org/10.22176/act18.3.172 
Declaración de las Naciones Unidas sobre los Pueblos Indígenas. Es imperativo promover respeto y aprecio por formas del saber que sean paralelas a la visión eurocéntrica, no sólo desde el decir, sino desde el hacer, concretando iniciativas que contemplen formas alternas de convivir y vivir con la música. Es importante mantener una visión crítica que desafíe las normas establecidas por una clase dominante, mediante la creación de espacios de diálogo para debatir ideas y poner en marcha proyectos que consideren la perspectiva de los pueblos indígenas. Éstas no se pueden definir bajo una mirada egocéntrica, sino que su identidad debe claramente representar los propios deseos, aspiraciones y visiones del mundo que las culturas indígenas guardan de sí mismas. La educación musical puede entonces convertirse en un área de oportunidad para crear espacios éticos que contribuyan al diálogo entre cosmovisiones distintas. Por lo tanto, es importante dar ese primer paso para que actuales y futuras generaciones de educadores(as) musicales se involucren en fortalecer espacios críticos donde la música no sea objeto para fomentar el menosprecio y la discriminación de unas personas hacia otras. Por el contrario, se deben fomentar espacios para el diálogo en los que las músicas sean parte viva y vigente de las diversas culturas y cosmovisiones que existen en el mundo.

\section{Acerca del autor}

Héctor Miguel Vázquez Córdoba es originario de Naolinco (Veracruz, México) y candidato doctoral en la Universidad de Victoria (Canadá). Su tesis doctoral plantea la incorporación de la música de raíces indígenas en el currículo nacional mexicano. Héctor cuenta con una Licenciatura en Música en Ejecución Musical (Universidad Veracruzana) y una Maestría en Educación (Instituto Tecnológico y de Estudios Superiores de Monterrey). Es violinista de la Orquesta Universitaria de Música Popular de la Universidad Veracruzana, y fundador y Director Ejecutivo de la asociación civil sin fines de lucro Mateo Oliva Oliva, y Director del Festival Internacional de Música Naolinco. El presente artículo forma parte del proyecto de investigación Building an appreciation for Indigenous cultures in Mexico via music eduation, el cual cuenta con el apoyo financiero del Social Sciences and Humanities Research Council of Canada (SSHRC).

\section{Referencias}

Albán, Álvaro. 2008. El origen colonial de las diferencias del desarrollo entre países: El neoinstitucionalismo e Hispanoamérica. Revista de Economía Institucional 10 (19): 235-64.

Vázquez Córdoba, Héctor Miguel. 2019. (Re)centrando las perspectivas indígenas en la educación musical en América Latina. Action, Criticism, and Theory for Music Education 18 (3): 172-99. http://doi.org/10.22176/act18.3.172 
Archibald, Marian. 2011. The inclusion of musical knowledge and perspectives of a First Nation in three Ontario mainstream schools. Vancouver, Canadá: Universidad de la Columbia Británica.

Beaucage, Pierre. 2000. Más allá de lo jurídico. Reflexiones sobre procesos autonómicos indígenas en América. En Los retos de la etnicidad en los estadosnación del siglo XXI, editado por Reina Leticia, 299-322. Centro de Investigaciones y Estudios Superiores de Antropología Social: México.

Bermúdez, Egberto. 2010. Música Indígena Colombiana. Maguaré 5: 85-97.

Bourdieu, Pierre. 1984. Distinction. Cambridge, Massachusetts: Harvard University Press.

Bowman, Wayne. 2002. Educating musically. En The new handbook of research on music teaching and learning: A project of the music educators national conference, editado por Richard Colwell y Carol Richardson, 63-84. Nueva York, Oxford: Oxford University Press.

Bradley, Deborah. 2012. Good for what, good for whom?: Decolonizing music education philosophies. En The Oxford handbook of philosophy in music education, editado por Wayne Bowman y Ana Lucia Frega, 409-433. Nueva York: Oxford University Press.

Chance, John. 1998. La hacienda de los Santiago en Tecali, Puebla: Un cacicazgo nahua colonial, 1520-1750. Historia Mexicana 47 (4): 689-734.

Chiilisa, Bagele. 2012. Indigenous research methodologies. Thousand Oaks, CA: Sage.

CONAPO. 2015. Infografía: Población indígena. Recuperado de: https://www.gob.mx/cms/uploads/attachment/file/121653/Infografia_INDI_FINAL_08082016.pdf

Devalle, Susana B.C. 2000. Concepciones de la etnicidad, usos, deformaciones y realidades. En Los retos de la etnicidad en los estados-nación del siglo XXI, editado por Reina Leticia, 31-44. Centro de Investigaciones y Estudios Superiores de Antropología Social: México.

Emmerson, Simon. 2000. Crossing cultural boundaries through technology? En Music, electronic media and culture, editado por Simon Emmerson, 115137. Ashgate: Vermont.

Vázquez Córdoba, Héctor Miguel. 2019. (Re)centrando las perspectivas indígenas en la educación musical en América Latina. Action, Criticism, and Theory for Music Education 18 (3): 172-99. http://doi.org/10.22176/act18.3.172 
Ermine, Willie. 2007. The ethical space of engagement. Indigenous Law Journal at the University of Toronto Faculty of Law 6 (1): 193-203.

García, José Luis. 2012. Naturaleza y límites de la educación comparada. En La educación comparada en tiempos de globalización, editado por José Luis García y M. J. García \& Elisa Gavani Starkie, 15-42. Madrid, España: Universidad Nacional de Educación a Distancia (UNED).

Garzón, Pedro. 2018. Colonialidad (jurídica). Eunomía. Revista en Cultura de la Legalidad (14): 206-214.

Garzón, Pedro. 2013. Pueblos indígenas y decolonialidad sobre la colonización epistemológica occidental. Andamios 10 (22): 305-331.

Giménez, Gilberto. 2000. Identidades étnicas: estado de la cuestión. En Los retos de la etnicidad en los estados-nación del siglo XXI, editado por Reina Leticia, 45-70. Centro de Investigaciones y Estudios Superiores de Antropología Social: México.

Goble, J. Scott. 2010. What's so important about music education? Londres y Nueva York: Routledge.

Goble, J. Scott. 2015. Music or musics? An important matter at hand. Action, Criticism, and Theory for Music Education 14 (3): 27-42.

Hess, Juliet. 2015. Decolonizing music education: Moving beyond tokenism. International Journal of Music Education 33 (3): 336-47.

Hess, Juliet. 2017. Equity and music education: Euphemisms, terminal naivety, and Whiteness. Action, Criticism, and Theory for Music Education 16 (3): 1547.

Kovach, Margaret. 2009. Indigenous methodologies: Characteristics, conversations and contexts. Toronto, Canadá: University of Toronto Press.

Locke, Terry, y Lauren Prentice. 2016. Facing the indigenous 'Other': Culturally responsive research and pedagogy in music education. The Australian Journal of Indigenous Education 45 (2): 139-51.

Martínez, Jorge. 2002. La música indígena y la identidad: los espacios musicales de las comunidades de mapuche urbanos. Revista Musical Chilena 56: 21-44.

MacDonald, Raymond A. R., David J. Hargreaves, y Dorothy Miell. 2002. Musical identities. Oxford y Nueva York: Oxford University Press.

Vázquez Córdoba, Héctor Miguel. 2019. (Re)centrando las perspectivas indígenas en la educación musical en América Latina. Action, Criticism, and Theory for Music Education 18 (3): 172-99. http://doi.org/10.22176/act18.3.172 
Menegus, Margarita. 2002. Balance historiográfico. Reflexiones sobre el cacicazgo en la Nueva España. Estudios de Historia Novohispana 27: 213-30

Mignolo, Walter, y Catherine Walsh. 2018. On decoloniality: Concepts, analytics, praxis. Durham, Carolina del Norte: Duke University Press.

Organización de las Naciones Unidas. 2008. Declaración de las Naciones Unidas sobre los pueblos indígenas. Consultado el 10 de Diciembre de 2017. http://www.un.org/esa/socdev/unpfii/documents/DRIPS_es.pdf

Pacheco, Veronica. 2016. Music, participation, and the mountain: Rain ceremonies in Chicontepec, Veracruz, México. Trans: Revista transcultural de música 20: 1-22.

Pujadas, Joan J. 2000. Minorías étnicas y nacionales frente al Estado y la globalización: reflexiones desde el otro lado del Atlántico. En Los retos de la etnicidad en los estados-nación del siglo XXI, editado por Reina Leticia, 101-121. Centro de Investigaciones y Estudios Superiores de Antropología Social: México.

Quijano, Aníbal. 1992. Colonialidad y modernidad/racionalidad. Perú Indígena 13 (29): 11-20.

Quijano, Aníbal. 200o. Coloniality of power, Eurocentrism and Latin America. Nepantla, Views from South 1(3): 533-80.

Ruddock, Eve. 2017. Misconceptions underplay Western ways of musicking: A hermeneutic investigation. Action, Criticism, and Theory for Music Education 14 (1): 66-92.

Rodríguez, Javier. 2006. Resistencia y confrontación en Argentina. Negación y exclusión de los pueblos indígenas. Gaceta de Antropología Social 22.

Rosabal-Coto, Guillermo. 2013. La herida colonial en los orígenes de la educación musical escolar costarricense. Revista Estudios 27: 278-95.

Rosabal-Coto, Guillermo. 2014. "I did it my way!" A case study of resistance to coloniality in music learning and socialization. Action, Criticism, and Theory for Music Education 13 (1): 155-87.

Rosabal-Coto, Guillermo. 2016. Music learning in Costa Rica: A postcolonial institutional ethnography. Helsinki, Finlandia: Academia Sibelius de la Universidad de las Artes de Helsinki.

SEP. 2016. Propuesta curricular para la educación obligatoria 2016. México: Secretaría de Educación Pública.

Vázquez Córdoba, Héctor Miguel. 2019. (Re)centrando las perspectivas indígenas en la educación musical en América Latina. Action, Criticism, and Theory for Music Education 18 (3): 172-99. http://doi.org/10.22176/act18.3.172 
SEP. 2017. Aprendizajes clave para la educación integral. Ciudad de México: Secretaría de Educación Pública.

Shifres, Favio, y Daniel Gonnet. 2015. Problematizando la herencia colonial en la educación musical. Epistemus 3 (2): 51-67.

Small, Christopher. 1998. Musicking: The meanings of performing and listening. Middletown, Connecticut: Wesleyan University Press.

Smith, Linda Tuhiwai. 2012. Decolonizing methodologies: Research and Indigenous peoples. Londres, Reino Unido: Zed Books.

Sturman, Janet. 2016. The course of Mexican music. Nueva York: Routledge, Taylor \& Francis Group.

Styres, Sandra. 2017. Pathways for remembering and recognizing indigenous thought in education: Philosophies of iethi'nihsténha ohwentsia'kékha (Land). Toronto, Canadá: University of Toronto Press.

Thekkevallyara, Varghese. 2013. The postcolonial other: Insights into the colonial underpinnings of mandatory clerical celibacy among the St. Thomas Christians of India. Theology \& Sexuality 19 (2): 143-62.

Tuck, Eve, y Marcia McKenzie. 2015. Place in research: Theory, methodology, and methods. Londres, Reino Unido: Routledge, Taylor \& Francis Group.

Tutino, John. 2000. Comunidad, independencia y nación: las participaciones populares en las historias de México, Guatemala y Perú. En Los retos de la etnicidad en los estados-nación del siglo XXI, editado por Reina Leticia, 125-51. Centro de Investigaciones y Estudios Superiores de Antropología Social: México.

Vázquez, Héctor. 2017. La educación musical como oportunidad para el aprendizaje de la cosmovisión de los pueblos indígenas en el sistema educativo mexicano: El caso de La Huasteca. Revista Internacional de Educación Musical (5): 103-110. doi: 10.12967 /RIEM-2017-5-p103-110.

Viqueira, Juan Pedro. 2011. Indios y ladinos, arraigados y migrantes en Chiapas: Un esbozo de historia demográfica de larga duración. En Caras y máscaras del México étnico. La participación indígena en las formaciones del Estado Mexicano, editado por A. Roth Seneff, 221-70. Colegio de Michoacán: México.

Wilson, Shawn. 2008. Research is ceremony. Indigenous research methods. Winnipeg, Canadá: Fernwood Publishing.

Vázquez Córdoba, Héctor Miguel. 2019. (Re)centrando las perspectivas indígenas en la educación musical en América Latina. Action, Criticism, and Theory for Music Education 18 (3): 172-99. http://doi.org/10.22176/act18.3.172 


\section{Notas}

${ }^{1}$ Se mantiene el género masculino en referencia al colonizador, pues se considera que la colonización que nos ocupa en este artículo, fue emprendida por varones, mediante violencia enraizada en el tipo de masculinidad de éstos (véase RosabalCoto 2016).

2 En el texto la autora hace énfasis en el uso de la letra "L" mayúscula en la palabra Land (Tierra) para representar el concepto de lethi'nihsténha Ohwentsia'kékha, que significa "nuestra madre Tierra" (por dicho motivo hago lo mismo en la traducción al español). Con esto, la autora distingue cuando se refiere a la tierra como lugar, y cuando lo hace desde la perspectiva de Tierra como concepto filosófico. "El concepto que se deriva de lethi' nihsténha Ohwentsia' kékha (Tierra) conlleva seriamente tener en cuenta todas las responsabilidades que tenemos en nuestras relaciones con ella y con cada uno de nosotros a todas nuestras relaciones (animadas/inanimadas)" (Styres 2017, 18).

3 En el contexto de la colonia, se entiende como una organización social donde el cacique (personaje ligado a la nobleza indígena) ejerce control político sobre un espacio de tierra determinado (Chance 98; Menegus 2009).

4 Término que describe a una persona que tiene raíces indígenas pero que no se identifica como tal, por lo cual hace uso del español como lengua de comunicación y abandona cualquier simbolismo que lo conecte con su herencia indígena (Viqueira 2011).

Vázquez Córdoba, Héctor Miguel. 2019. (Re)centrando las perspectivas indígenas en la educación musical en América Latina. Action, Criticism, and Theory for Music Education 18 (3): 172-99. http://doi.org/10.22176/act18.3.172 